\title{
Duct-to-Mucosa Pancreaticojejunostomy with Less Serosal Stitches: A Different Approach to Well-known Problem
}

\author{
Ismail Sert ${ }^{1}$, Degercan Yesilyurt ${ }^{2}$, Suleyman Caglar Ertekin ${ }^{3}$, Cem Karaali $^{2}$ and Mustafa Emiroglu ${ }^{2}$ \\ ${ }^{1}$ Department of General Surgery and Transplantation, Tepecik Training and Research Hospital, Izmir, Turkey \\ ${ }^{2}$ Department of General Surgery, Tepecik Training and Research Hospital, Izmir, Turkey \\ ${ }^{3}$ Department of General Surgery, Egepol Surgery Hospital, Izmir, Turkey
}

\begin{abstract}
Objective: To describe a new approach (duct-to-mucosa pancreaticojejunostomy with less serosal stiches) for postoperative pancreatic fistula (POPF) in pancreaticoduodenectomy.

Study Design: An observational study.

Place and Duration of Study: Tepecik Training and Research Hospital, Izmir, Turkey, between January 2019 and May 2020.

Methodology: Medical records of 45 patients, who underwent pancreaticoduodenectomy by the same general surgeon between January 2019 and May 2020, were reviewed retrospectively. Pylorus-preserved pancreaticoduodenectomy was performed for all patients. Duct-to-mucosa PJ with less serosal suture technique was used for all patients in reconstruction after pancreaticoduodenectomy. Definition of the ISGPS was used for the POPF and only grade B and C fistulas were accepted as clinically relevant POPF. Here, the descriptive measures were reported.

Results: Seventeen (17) of the forty-five (45) patients were females and median age was sixty- six (66) years. The majority of the underlying disease was pancreatic adoneocarcinoma. Hyperbilirunemia was seen in 15 patients. Median operation time was 360 minutes. Number of patients with pancreatic duct size $<3 \mathrm{~mm}$ was five. Rate of soft pancreas texture was $33.3 \%$. Lastly, the number of patients that underwent vascular resection or additional organ resection were $6(13.3 \%)$ and 8 (17.8\%), respectively. Clinically relevant POPF according to ISGPS was seen in 6 patients (grade B:4 and grade C:2). The most prevalent postoperative complication was surgical site infection at a rate of $40 \%$. There was no POPF related mortality.

Conclusion: Two-layer duct-to-mucosa pancreaticojejunostomy with less serosal stitches technique has acceptable pancreatic fistula rates. This technique could be used by surgeons who are faced with challenges with the duct-to-mucosa anastomosis due to aforementioned causes. Large multi-centre randomised future studies are required to confirm these findings.
\end{abstract}

Key Words: Postoperative pancreatic fistula, Surgical technique, Duct-to-mucosa pancreaticojejunostomy, Less serosal stiches.

How to cite this article: Sert I, Yesilyurt D, Ertekin SC, Karaali C, Emiroglu M. Duct-to-Mucosa Pancreaticojejunostomy with Less Serosal Stitches: A Different Approach to Well-known Problem. J Coll Physicians Surg Pak 2022; 32(01):75-80.

\section{INTRODUCTION}

Pancreaticoduodenectomy is widely used as a standard treatmentfor many benign or malign lesions located in the periampullary or pancreas head region. Advances in the surgical technique and perioperative management helped reduce mortality rates by about $5 \%$; however, clinically relevant postoperative pancreatic fistula (POPF) and its complications are still the most troublesome. ${ }^{1}$ Depending on the definition used, POPF rates range between $5-40 \%$ in the literature. ${ }^{2,3}$ POPF potentially contributes to intra-abdominal abscesses, hemorrhage, sepsis and mortality. Many refinements of procedures have been introduced to prevent the POPF. ${ }^{1,4}$

Correspondence to: Dr. Ismail Sert, Department of General Surgery and Transplantation, Tepecik Training and Research Hospital, İzmir, Turkey

E-mail: caglarertekin@gmail.com

Received: February 18, 2021; Revised: April 28, 2021;

Accepted: June 01, 2021

DOI: https://doi.org/10.29271/jcpsp.2022.01.75
Technical and surgical risk factors, defined for development of POPF, may be summarised as small main pancreatic duct ( $\leq 3$ $\mathrm{mm}$ ), soft pancreas, posterior location of the main duct, underlying disease pathology, (non dilated pancreatic duct), decreased pancreatic blood supply of the pancreatic cut surface and surgical experience. ${ }^{5}$ Among them, surgical technique, blood supply of the pancreas cut surface, and surgical experience can be isolated as modifiable risk factors.

In literature, 61 different pancreas anastomosis techniques are defined until now. ${ }^{1}$ According to the position statement by the International Study Group of Pancreatic Surgery (ISGPS) recently, the most frequently used reconstruction technique after pancreaticoduodenectomy is pancreaticojejunostomy (PJ) with utilisation rate of $88.7 \%$. ${ }^{6}$ Anastomosis between the pancreatic stump and the jejunum can be performed by using various techniques ranging duct-to-mucosa or invagination either end-to-end or end to side. Duct-to-mucosa technique is extensively used for PJ anastomosis. ${ }^{6,7}$ Variety and heterogeneity of the anastomosis techniques make it challenging to compare them against each other in terms of superiority (or inferiority) on outcomes of different reconstruction techniques. 
In situations like thin and soft pancreatic tissue, posterior location of the pancreatic main duct and edema of the jejunal segment due to prolonged operation time, after posterior serosal suture, performing the duct-to-mucosa PJ anastomosis becomesvery difficult, or even impossible. Furthermore, a well-known, important factor for the duct-to-mucosa PJ is impaired blood supply of the pancreas cut surface. It adversely affects the outcomes of the duct-to-mucosa PJ. The technique described in this study (the duct-to-mocosa PJ with less serosal stiches) is a novel approach to overcome above-mentioned, unresolved problems and challenging situations suggested by a transplant surgeon in his early career of hepatopancreaticobiliary surgery.

The aim of this study was to determine the results of patients with POPF, who underwent duct-to-mucosa PJ with less suture.

\section{METHODOLOGY}

Medical records of consecutive 45 patients, who underwent pancreaticoduodenectomy at Tepecik Training and Research Hospital, Izmir, Turkey, by the same general surgeon between Jan 2019 and May 2020, were reviewed retrospectively. Pylorus preserved pancreaticoduodenectomy was performed for all patients. Additional organ or vascular resections were performed for eight patients (17.8\%) and six patients (13.3\%), respectively. Duct-to-mucosa PJ with less serosal suture technique was used for all patients in reconstruction after pancreaticoduodenectomy.

Demographic data of the patients (age, gender, comorbidities and alike) and perioperative data (texture of the pancreas, size of pancreatic duct, duration of the operation, use of pancreatic stent and alike) and postoperative follow-up (POPF, delayed gastric emptying morbidities, amylase level of drain liquid, hospital stay, mortality within PO 30 days and alike) were documented in detail. Drain amylase levels were checked atPO 0 and 3 day in all patients.

Octreotide was not used for prophilaxis of POPF. Additionally, topical application of the fibrin glue or omental wrapping technique was not used.

Definition of the ISGPS was used for the POPF and only grade $B$ and $\mathrm{C}$ fistulas were accepted as clinically relevant POPF. ${ }^{8,9}$ Pancreatic main duct size was categorised into three parts: less than $3 \mathrm{~mm}$, between 3 and $8 \mathrm{~mm}$, and larger than $8 \mathrm{~mm}$. Pancreatic gland texture was also defined as soft/normal or hard/fibrotic. The degree of pancreatic margin mobilisation was measured intraoperatively with a sterile ruler from the tip of the divided pancreas to the limit of the fully mobilised pancreatic paranchyma on its posterior aspect.

All the operations were performed by the same transplant surgeon in his early career of hepatopancreaticobiliary surgery. In all cases, anastomosis were performed by using a 2.5 times magnified surgical loop. All the procedures were performed on the same manner and the surgical procedure was not modified during the study period. Standard and generally accepted pancreaticoduodenectomy was performed in all cases. Although the authors usually performed pylorus preserved pancreaticoduodenectomy depending on the preoperative observations; but for advanced cases, the authors performed classic pancreaticoduodenectomy.

This study was approved by the local Ethics Committee of Tepecik Training and Research Hospital, Izmir, Turkey.

The data were assessed by using the SPSS version 22.0 (SPSS, Chicago. IL). Only descriptive measures (numbers, percentages, median, minimum and maximum) were reported due to lack of control group in this study, as the main purpose of this study is to describe a surgical technique.

A scalpel was used to sharply transect the pancreas at the left site of the portal vein. In some cases, WATSA procedure was performed to ensure R0 surgical resection margin. Pancreatic resection margin was sent for frozen section evaluation only for selected cases.

Two-stay hemostatic sutures were neverused. After the pancreaticoduodenectomy specimen was removed, hemostasis of the pancreatic stump was achieved by $5 / 0$ non-absorbable sutures or bipolar cautery. Moreover, pancreas remnant was not dissected free extensively $(2-3 \mathrm{~cm})$ from the retroperitoneum and splenic vein, but it is mobilised only approximately just $1 \mathrm{~cm}$ to ensure the outer layer stiches.

Transected jejunum is prepared in an antecolic manner for tension-free pancreaticojejunostomy and hepaticojejunostomy.

Double needles 5/0 absorbable monofilament suture needle was inserted from the pancreatic duct margin and pancreatic duct wall was observed to go as deep as possible. Additionally, this process should be performed with in-out needle movement and each suture should be held separately with a hemostat. Seven sutures were used with a clockwise pattern at $5,7,3,9,11,12,1$ locations, respectively (Figure 1). Then a small, full thickness enterotomy was performed along antimesenteric site, 4-5 cm distal to the jejunal stump. Firstly, clamped sutures at $5,7,3,9 o^{\prime}$ 'lock were respectively placed in an in-out direction through the enterotomy by the full thickness of the jejunum. Note that exit of these sutures should follow their o'clock pattern, if possible. And these sutures were gently tightened after approximation of the pancreatic and jejunal stump. All of the knots were tied on the outside. In all cases, a $15 \mathrm{~cm}$ stent was inserted to the pancreatic duct for $1-2 \mathrm{~cm}$ deep and remaining length was inserted into enterotomy. The stent should fit loosely because the size of the stent depends on the pancreatic duct size. Then, other remaining sutures at 11,12 and $10^{\prime}$ clock were placed in-out direction through the enterotomy. To fix the stent, 12 o'clock suture was used. All knots were tied gently. Duct-to-mucosa anostomosis was then completed.

Only two simple interrupted sutures ( $3 / 0$ absorbable monoflament) were used for the posterior outer layer. Jejunal part was lifted gently from the anterior position and a simple suture was placed between posterior superior and posterior inferior border of the paranchyma of the pancreatic stump and its counterpart of the jejenunal seromuscularlayer (Figures 2-3). 


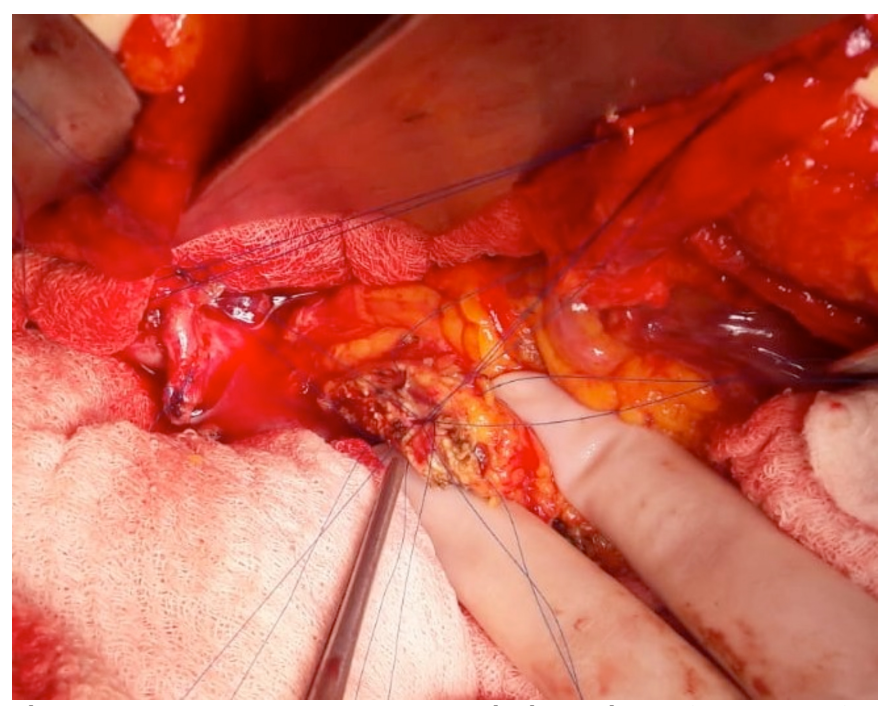

Figure 1: Duct-to-mucosa anostomosis inner layer 3-9-5-7-11-12-1 o'clock sutures.

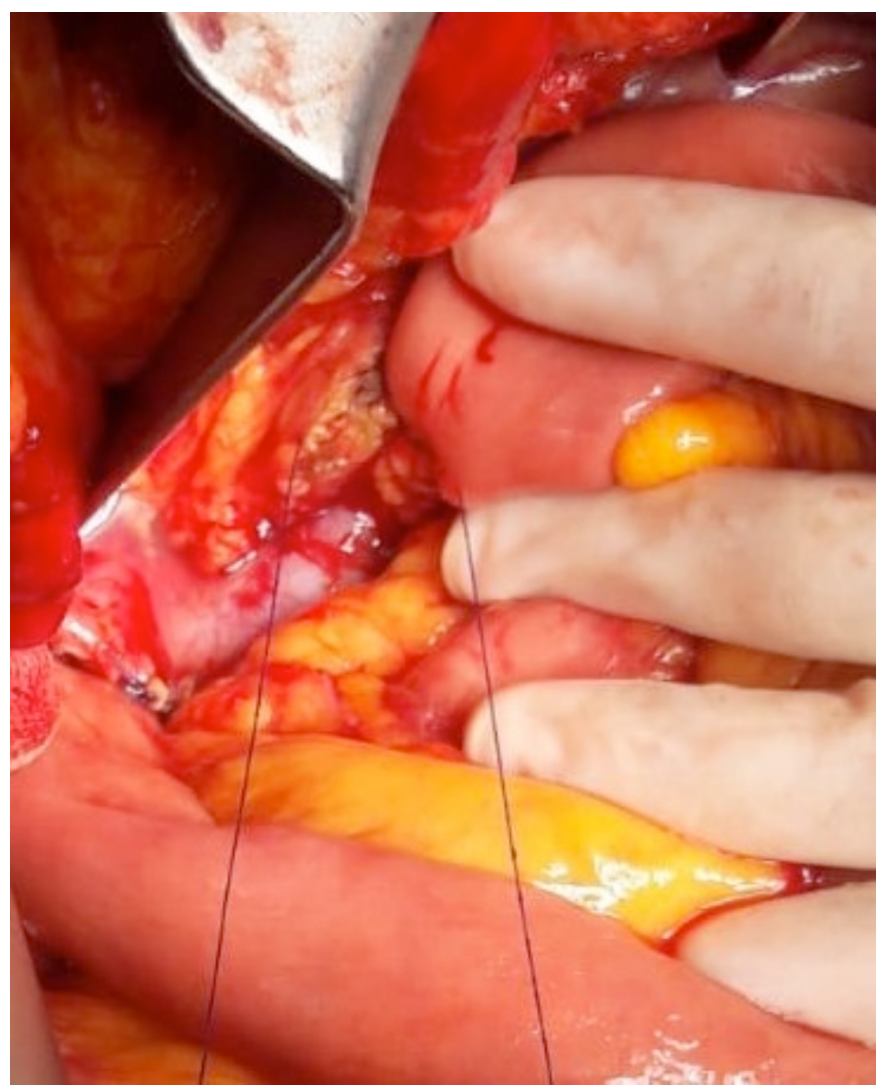

Figure 2: Outerserosal layer posteriorsuperiorsutures.

Only threesimple interrupted sutures (3/0 absorbablemonofilament sutures) were placed for the anterior outer layer. These sutures were placed between anterior superior, middle and anterior inferior part of the parenchyma of the pancreatic stump and its counterparts of the jejenal seromuscular layer (Figure 4). When tying, the knot should be pushed gently not to tear the pancreatic parenchyma.

Hepaticojejunostomy was performed $10-20 \mathrm{~cm}$ proximal to the $\mathrm{PJ}$ to ensure tension-free anastomosis. Suture technique was resumed with $4 / 0$ absorbable monofilament suture for hepaticoje- junostomy. Two close simple sutures were placed at the far corner. After tightening these two sutures, they should be tied together. Posterior suture was used on the posterior wall of the anastomosis; and anterior suture was used on the anterior wall of the hepaticojejunostomy. Then they were tied to each other on anterior wall. Additionally, two corner stay sutures were placed between hepatic duct and jejenum to reinforce the anostomosis.

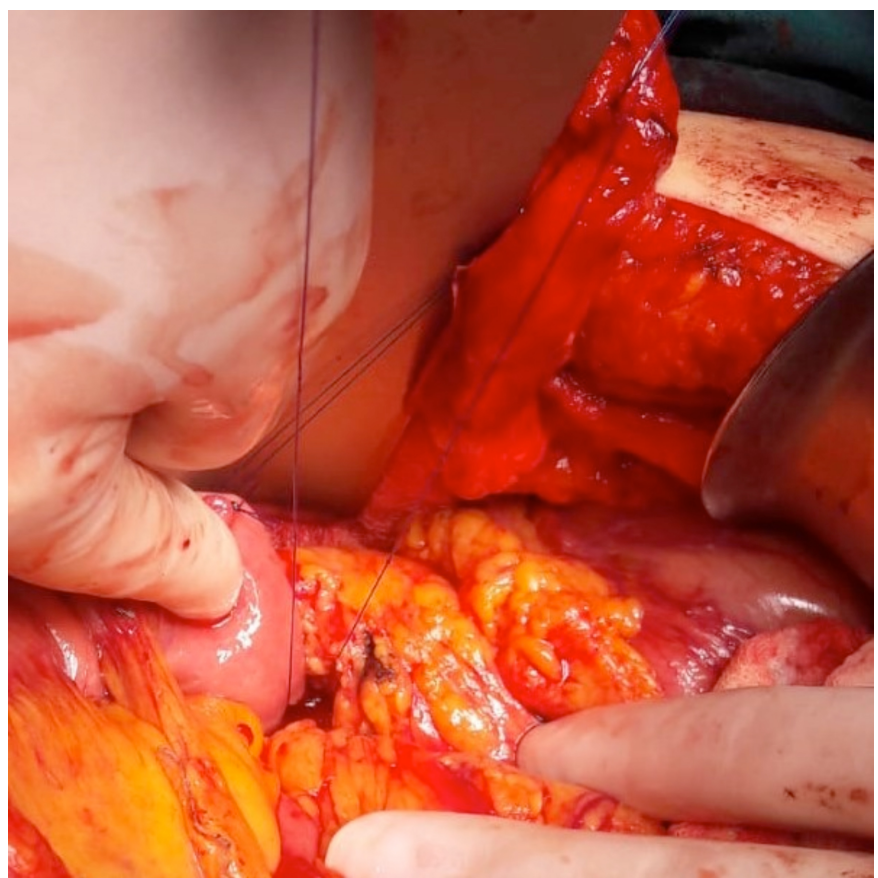

Figure 3: Outerserosal layer posteriorinferiorsutures.

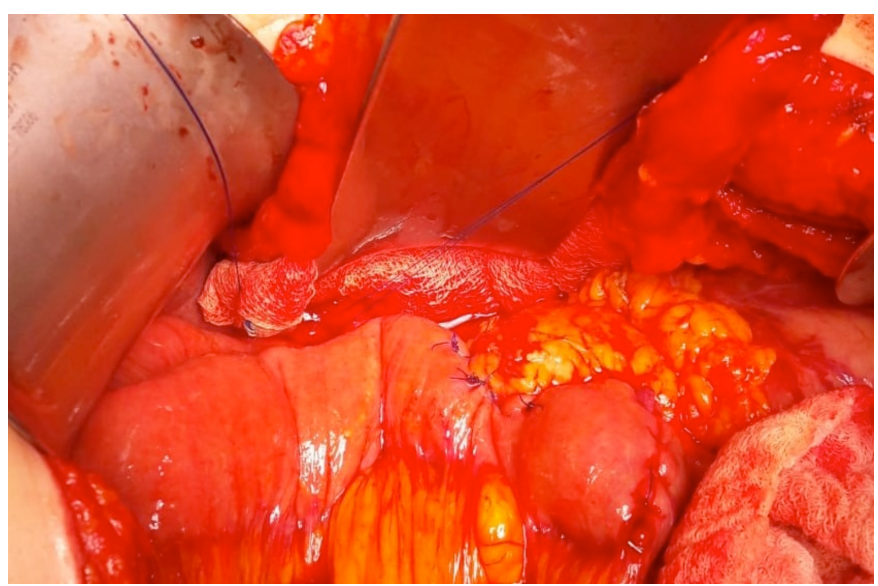

Figure 4: Outerserosal layeranteriorsutures.

After checking the viability of the duodenal part, duodenojejunostomy anostomosis was performed approximately $40 \mathrm{~cm}$ proximal to the $\mathrm{HJ}$ by two layer manner, using $3 / 0$ absorbable monofilament suture.

After the anastomosis were completed, two nelathon drains were routinely placed to facilitate postoperative observation and drainage fluid monitoring. One drain was placed on the right upper abdominal wall by passing posteriorly the $\mathrm{HJ}$ to inferior posterior side of the pancreaticojejunostomy anastomosis. The other drain was placed on the left upper abdominal wall to anterior side of the pancreaticojejunostomy anostomosis. 


\section{RESULTS}

The duct-to-mucosa PJ with less suture technique was performed on 45 consecutive patients, who underwent PD by the same surgeon. Seventeen of the patients were females; and median age was 66 years. The majority of the underlying disease was pancreatic adenocarcinoma. Number of patients with ASA score 3 and 4 were 24 (53.3\%) and 2 (4.4\%), respectively. Hyperbilirubinemia was seen in 15 patients. Patient characteristics were summarised in Table I.

Distance of pancreatic margin (PM) mobilisation was $<1 \mathrm{~cm}$ for all cases (PM1). Median operation time was 360 minutes. Number of patients with pancreatic duct size $\leq 3 \mathrm{~mm}$ was five (11.1\%). Rate of soft pancreas texture was $33.3 \%$. The number of the patients who underwent vascular resection or additional organ resection were $8(17.8 \%)$ and $6(13.3 \%)$, respectively. Pancreatic internal stent during PJ could not be performed for only two patients due to technical problems. Intraoperative data is summarised in Table ll.

Clinically, relevant POPF according to ISGPS was seen in 6 patients (grade $\mathrm{B}: 4$ patients and grade $\mathrm{C}: 2$ patients). The greatest postoperative complication was observed as surgical site infections $(40 \%)$. There was no POPF related mortality. Postoperative mortality within 30 days was $8.9 \%$ ( 4 patients). The postoperative course and complications are summarised in Table III.

Table I: Demographic data of the patients.

\begin{tabular}{|l|c|c|}
\hline & Number (\%) & $\begin{array}{c}\text { Median } \\
(\mathbf{m i n}-\mathbf{m a x})\end{array}$ \\
\hline Age & & $66(41-86)$ \\
\hline Gender: & $17(37.8)$ & \\
Female & $28(62.2)$ & \\
Male & $24(53.3)$ & \\
\hline ASA score: & $2(4.4)$ & \\
ASA 3 & & $6(1-11)$ \\
ASA 4 & & $26(20-35)$ \\
\hline Charlson comorbidity index & $22(48.9)$ & \\
\hline BMI & $15(33.3)$ & \\
\hline History of smoking & & $3.3(2.0-4.1)$ \\
\hline Preoperative biliary drainage & & $11.5(7.8-13.5)$ \\
\hline Albumin $(\mathrm{g} / \mathrm{dl})$ & & $280(90-320)$ \\
\hline Hemoglobin $(\mathrm{g} / \mathrm{dl})$ & & $2.4(1.0-3.2)$ \\
\hline Trombosit $\left(10^{3} \mathrm{uL}\right)$ & & \\
\hline Lymphocyte $\left(10^{3 *} \mathrm{uL}\right)$ & &
\end{tabular}

\section{Table II: Intraoperative data.}

\begin{tabular}{|l|c|c|}
\hline & Number (\%) & $\begin{array}{c}\text { Median } \\
\text { (min-max) }\end{array}$ \\
\hline Operation technique: & $45(100)$ & \\
Pylorus preserved pancreaticoduodenectomy & $15(33.3)$ & \\
\hline $\begin{array}{l}\text { Texture of pancreas: } \\
\text { Soft }\end{array}$ & $30(66.7)$ & \\
Hard & $5(11.1)$ & \\
\hline $\begin{array}{l}\text { Pancreatic duct size: } \\
\leq 3 \mathrm{~mm}\end{array}$ & $40(88.9)$ & \\
$>3 \mathrm{~mm}$ & $6(13.3)$ & \\
\hline Vascular resection & $8(17.8)$ & \\
\hline Additional Organ resections (colon resection, & & $360(210-620)$ \\
\hline splenectomy) & & \\
\hline Operation time (minutes) & & \\
\hline
\end{tabular}

Table III: Postoperative follow-up data.

\begin{tabular}{|l|l|c|}
\hline & Number (\%) & $\begin{array}{c}\text { Median } \\
\text { (min-max) }\end{array}$ \\
\hline
\end{tabular}

\begin{tabular}{|l|c|l|}
\hline POPF & $4(8.9)$ & \\
Grade B & $2(4.4)$ & \\
Grade C & $8(17.8)$ & \\
\hline Delayed gastric emptying & $2(4.4)$ & \\
\hline Bile leak & $2(4.4)$ & \\
\hline Gastrojejunostomy leak & $18(40)$ & \\
\hline Surgical site infection & $1(2.2)$ & \\
\hline Intraabdominal abscess & $3(6.7)$ & \\
\hline Re-operation & & $12(7-32)$ \\
\hline Hospital stay (days) & $4(8.9)$ & \\
\hline Mortality in postoperative 30 days & & \\
\hline
\end{tabular}

\section{DISCUSSION}

Pancreatic fistula is one of the unresolved problems after the pancreaticojejunostomy reconstruction. ${ }^{2,3}$ In this study, the rate of clinically relevant pancreatic fistula rate was $6-13 \%$. This rate is compatible with the literature and it should be reminded that all the procedures were performed by the same surgeon without previous experience on pancreaticoduodenectomy and reconstruction.

Many factors (patient age, obesity, smoking, biliary stenting, neoadjuvant therapy, nutritional status, tissue exture, duct size, type of resection, surgeon volume, blood loss, pathology type, post-op pancreatitis, etc.) associated with the pancreatic fistula formation were reported. ${ }^{7}$ When the present authors focus on peri-operative factors, herein it is realised that the modifiable risk factors are only an extension of the pancreatic remnant mobilisation, site of enteric drainage, operative time, blood loss, perfusion, fluids, use of stent, prophylactic, use of octreotide, and pancreatic anastomosis technique. ${ }^{7,9}$

Still many hepatobiliary surgeons focus on the modification of reconstruction techniques or sites, although more than 60 pancreas anastomosis techniques have been reported until now. ${ }^{1}$

For a technically successful anastomosis, the conditions of tension-free, supply optimal blood flowand unobstructed pancreatic secretion should be obtained. ${ }^{10}$ Surgical technique described in the present study is a modification of the two-layered duct-to-mucosa pancreatojejunostomy, using a pair-watch suturing technique; but it contains many modifications to overcome challenging situations, especially like posterior serosal stiches of the duct-to-mucosa anastomosis. ${ }^{11}$ Furthermore, present study is important to introduce the feasibility of less stiches for both duct-to-mucosa and outer serosal layer during PJ, when compared to the currenttechnique.

Firstly, while applying intraoperative two-layer duct-to-mucosa pancreaticojejunostomy technique, conditions like complicate anastomosis, and make it impossible to coexist. In order to reduce the negative effects of these problems on the application of duct-to-mucosa anastomosis, the authors applied the technique, which was described in detail.

Thin pancreatic tissue, posterior location of the main pancreatic duct, edema of the jejunal segment due to prolonged operation time, soft pancreatic texture, and main pancreatic duct size 
$<3 \mathrm{~mm}$.

There are some important points of this technique and their literature support. Although, some authors suggest that excessive mobilisation $(3-4 \mathrm{~cm}$ ) of the pancreatic remnant is necessary for a tension-free anastomosis during PJ. ${ }^{12,13}$ As previously underlined by Strasberg et al., the authors believe that adequate blood supply to the remnant pancreas is essential and mobilisation of the pancreatic remnant should be kept to a minimum as much as possible. Excessive mobilisation should be avoided. In all cases, the surgeons performed limited mobilisation, a distance $<1 \mathrm{~cm}$ from tip of the divided pancreas is achieved and stay sutures were never used.

In patients with thin pancreas tissue, posterior location of the pancreatic main duct, soft pancreas texture and edema of the jejunal segment was experienced, making the posterior outer layer sutures in continued or interrupted fashion very challenging and endangered the safe duct-to-mucosa PJ anastomosis. As a result, pancreatic duct sutures were first placed in-out manner, then posterior and lateral jejunal aperture sutures were introduced by in-out manner and finally the sutures were tied. After the introduction of the pancreatic stent, the anterior jejunal secure sutures were completed again by in-out manner and tied. In this way, the identification of the pancreatic duct was ensured. The number of stiches used during the duct-to-mucosa PJ changes, depends on the surgeons. ${ }^{13-17}$ In this technique, only a total of seven stiches were used for duct-to-mucosa anostomosis on $5,7,3,9,11,12,13$ o'clock locations.

The outer suture layer is required for protection of detachment of the PJ anastomosis, as previously reported. ${ }^{14,18}$ Running or interrupted suture techniques were generally used for the outer layer of the PJ, prior to inner layer anastomosis. Number of the stiches were commonly more than five. ${ }^{16,19-21}$ Outer layer sutures can be performed after inner layer of the duct-to- mucosa anastomosis was completed. ${ }^{14,18}$ In the present technique, the outer layer anastomosis was completed by using only five stiches for both the side (two stiches for posterior outer layer and three stiches for anterior outer layer) after performing the duct-to-mucosa anastomosis.

Modifiable risk factors for pancreatic fistula are limited and the surgical technique and modifications are one of them. ISGPS position statement suggests that experienced surgeons at high volume centres can decrease the incidence of POPF by using different techniques depending on the intraoperative situations. ${ }^{6}$ The same position statement expresses that: practice and mastery of a standardised technique can be a potential solution to overcome the complication of POPF for surgeons early in their career. ${ }^{6}$ The present study is a nice guide for the surgeons early in their career, and who want to practice in duct-to-mucosa technique.

\section{CONCLUSION}

Present study suggests that two-layer duct-to-mucosa pancreaticojejunostomy, with less serosal stitches technique, is feasible and has acceptable pancreatic fistula rates. This technique can be used by surgeons who face difficulties with the duct-to-mucosa anastomosis due to aforementioned causes.
Large multi-centre randomised future studies are required to confirm these findings.

\section{ETHICALAPPROVAL:}

This study was approved by the local Ethics Committee of Tepecik Training and Research Hospital, Izmir, Turkey.

\section{PATIENTS' CONSENT:}

Informed consent was taken from all patients in the study.

\section{CONFLICT OF INTEREST:}

The authors declared no conflict of interest.

\section{AUTHORS' CONTRIBUTION:}

IS: Conception or design of the work, or the acquisition, analysis, or interpretation of data for the work, drafting the work or revising it critically for important intellectual content, final approval of the version to be published.

DY: Conception or design of the work; or the acquisition, analysis or interpretation of data for the work.

SCE: Conception or design of the work, or the acquisition, analysis, or interpretation of data for the work, final approval of the version to be published.

CK, ME: Analyses, or interpretation of data for the work.

\section{REFERENCES}

1. Daamen LA, Smits FJ, Basselink MG, Bush OR, Borel Rinkes IH, Van Santvoort HC, et al. A web-based overview, systemic review and meta-analysis of pancreatic anostomosis techniques following pancreatoduodenectomy. HPB (Oxford) 2018; 20(9): 777-785. doi: 10.1016/j.hpb.2018.03.003.

2. Cameron JL, Rial TS, Coleman J, Belcher KA. One thousand consecutive pancreaticoduo denectomies. Ann Surg 2006; 244(1):10-15. doi: 10.1097/01.sla.0000217673.04165.ea.

3. Fernandez-Cruz L, Sabater L, Fabregat J, Boggi U. Complications after pancreaticoduodenectomy. Cir Esp 2012; 90(4):222-232.

4. Bassi C, Dervenis C, Butturini G, Fingerhut A, Yeo C, Izbicki J, et al. Postoperative pancreatic fistula: An international study group (ISGPF) definition. Surgery 2005; 138(1): 8-13. doi: 10.1016/j.surg.2005.05.001.

5. Gauma DJ, van Geenen RC, van Gulik TM, de Haan RJ, de Wit LT, Busch OR, et al. Rates of complications and death after pancreaticoduodenectomy: Risk factors and impact of hospital volume. Ann Surg 2000; 232(6):786-95. doi: 10.1097/00000658-200012000-00007.

6. Shrikhande SV, Sivasanker M, Vollmer CM, Friess $H$, Basselink MG, Fingerhut $A$, et al. Pancreatic anostomosis after pancreatoduodenectomy: A position statement by the International study group of pancreatic surgery (ISGPS). Surgery 2016; 161(5): 1221-34. doi: 10.1016/j.surg.2016. 11.021.

7. Soreide K, Healey AJ, Mole DJ, Parks RW. Pre- Peri- and Post-operative factor for development of pancreatic fistula after pancreatic surgery. HPB(Oxford) 2019; 21(12): 1621-31. doi: 10.1016/j.hpb.2019.06.004.

8. Bassi C, Marchegiani G, Dervenis C, Sarr M, Abu Hilal M, Adham M, et al. The 2016 update of the International Study 
Group (ISGPS) definition and grading of postoperative pancreatic fistula: 11 years after. Surgery 2017; 161(3): 584-91. doi: 10.1016/j.surg.2016.11.014.

9. Shukla PJ, Barreto SG, Fingerehut A, Bassi C, Buchler MW, Dervenis $C$, et al. Toward improving uniformity and standardiSation in the reporting of pancreatic anostomosis: A new classification system by the International study group of pancreatic surgery (ISGPS). Surgery 2010; 147(1):144-53. doi: 10.1016/j.surg.2009.09.003.

10. Shrikhande SV, Barreto G, Shukla PJ. Pancreatic fistula after pancreaticoduodenectomy: The impact of a standardised technique of pancre-aticojejunostomy. Langenbeck's Arch Surg 2008; 393(1):87-91. doi: 10.1007/s00423-0070221-2.

11. Azumi $Y$, Isaji $S$, Kato $H$, Nobuoka $Y$, Kuriyama N, Kishiwada $M$, et al. A standardised technique for safe pancreaticojejunostomy: Pair-watch suturing technique. World J Gastrointest Surg 2010; 2(8): 260-4. doi: 10.4240/wjgs. v2.i8.260.

12. Yeo CJ, Cameron JL, Maher MM, Sauter PK, Zahurak ML, Talamini MA, et al. A prospective trial of pancreaticogastrostomy versus pancreaticojejunostomy after pancreaticoduodenectomy. Ann Surg 1995; 222(4): 580-8. doi: 10.1097/00000658-199510000-00014.

13. Zgraggen $K$, Uhl W, Friess $H$, Büchler MW. How to do a safe pancreatic anostomosis. J Hepatobiliary Pancreat Surg 2002; 9(6):733-7. doi: 10.1007/s005340200101.

14. Kim M, Shin WY, Lee KY, Ahn SI. An intuitive method of duct-to-mucosa pancreaticojejunostomy after pancreaticoduodenectomy: Use of one-step circumferential interrupted sutures. Ann Hepatobiliarry Pancreat Surg 2017;
21(1):39-47. doi: 10.14701/ahbps.2017.21.1.39.

15. Zhang L, Zhipeng L, Wu X, Li Y, Zeng Z. Sealing pancreaticojejunostomy in combination with duct parenchyma to mucosa seromuscular one-layer anostomosis: A novel technique to prevent pancreatic fistula after pancreaticoduodenectomy. J Am Coll Surg 2015; 220(5):e71-7. doi: 10.1016/j.jamcollsurg.2014. 12.047.

16. Li R, Zhang W, Li Q. Modified pancreaticojejunostomy in pancreaticoduodenectomy for the treatment of periampullary tumor: 8 years of surgical experience. Med Sci Monit 2109; 25: 3788-95. doi: 10.12659/MSM.916837.

17. Hu BY, Leng JJ, Wan T, Zhang WZ. Application of singlelayer mucosa-to-mucosa pancreaticojejunal anostomosis in pancreaticoduodenectomy. World J Gastroinest Surg 2015; 7(11):335-44. doi: 10.4240/wjgs.v7.i11.335.

18. Bai X, Zhang Q, Gao S, Lou J, Li G, Zhang Y, et al. Duct-tomucosa vs. Invagination for pancreaticojejunostomy after pancreaticoduodenectomy: a prospective randomised controlled trial from a single surgeon. J Am Coll Surg 2016; 222(1):10-8. doi: 10.1016/j.jamcollsurg.2015.10.003.

19. Thapa PB, Maharjan DK, Regmi S. Pancreatic anostomosis: challanges and outcomes. J Surg Transplant Sci 2017; 5(3):1055.

20. Barreto SG, Shukla PJ. Different types of pancreaticoenteric anostomosis. Transl Gastroenteral Hepatol 2017; 2:89. doi: 10.21037/tgh.2017.11.02.

21. Katsaragakis S, Larentzakis A, Panousopoulos SG, Toutouzas KG, Theodorou D, Stergiopoulos S, et al. A new pancreaticojejunostomy technique: A battle against postoperative pancreatic fistula.World J Gastroenterol 2013; 19(27):4351-5. doi: 10.3748/wjg.v19.i27.4351. 